\title{
Diagnostic Challenge
}

\section{An unexpected cause of infantile dyspnea}

\author{
Dhimitri A. Nikolla, DO*; Jestin N. Carlson, MD, MSc*
}

Keywords: Paroxysmal Supraventricular Tachycardia,

Pediatric Dysrhythmias, Pediatric Heart Failure

\section{CASE HISTORY}

A fully vaccinated 7 -month-old male with no significant past medical history presented to the emergency department (ED) with his mother complaining of 3 days of worsening cough and tachypnea. His mother stated that he has begun belly-breathing and had significantly decreased oral intake over the past day. She denied fever, vomiting, diarrhea, rashes, lethargy, rhinorrhea, and wheezing.

His vital signs were temperature of $36.1^{\circ} \mathrm{C}$, heart rate (HR) of 130 beats/minute, respiratory rate (RR) of 60 breaths/minute, oxygen saturation of $94 \%$ on room air, and weight of $7.28 \mathrm{~kg}$. He appeared to be in moderate distress with accessory muscle use. His head and neck examination was normal without stridor. For his age, he had a normal HR and rhythm without a murmur. He was tachypneic, but his lung sounds were clear of wheezes, rhonchi, and rales. His abdomen was soft without tenderness or masses. He had strong distal pulses, and his capillary refill was less than 2 seconds.

His initial lab results were notable for a white blood cell count of $21.1 \times 10^{9} / \mathrm{L}$ and platelet count of $622 \times 10^{9} / \mathrm{L}$. A chest radiograph was obtained (Figure 1) and read by the radiologist as, "Perihilar haziness. Question bronchial infection. Correlate clinically." The patient was diagnosed with sepsis secondary to pneumonia, given a $20-\mathrm{ml} / \mathrm{kg}$ normal saline bolus, intravenous ceftriaxone, and admitted to the pediatrics floor.

Several hours later, a rapid response was called to the patient's bedside for tachycardia. The patient's HR had risen to 300 beats/minute without significant variability. His other vital signs were RR 40, oxygen saturation of
$92 \%$, and blood pressure of $62 / 23 \mathrm{~mm} \mathrm{Hg}$. Despite the tachycardia, the patient's cardiopulmonary examination was normal, including capillary refill, but hepatomegaly was now noted. An electrocardiogram (ECG) was obtained showing a narrow complex tachycardia with $\mathrm{P}$ waves, QRS alternans, and a ventricular rate of 298 beats/minute (Figure 2).

\section{QUESTION}

The most likely cause of the infant's presenting dyspnea was:
A) Pneumonia
B) Structural heart disease
C) Paroxysmal supraventricular tachycardia with acute congestive heart failure

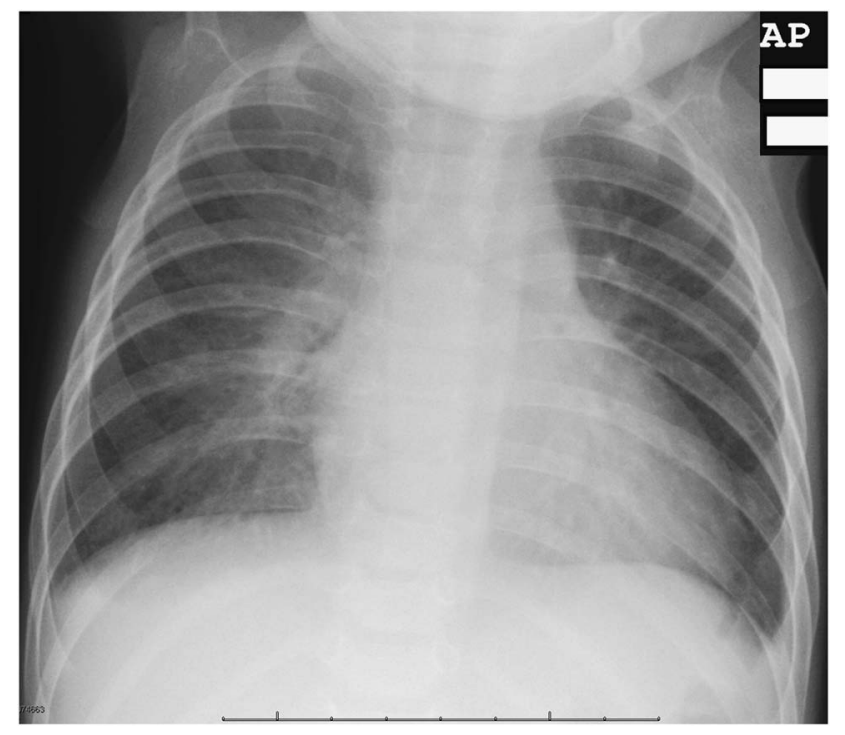

Figure 1. Patient's chest radiograph.

From the *Department of Emergency Medicine, Allegheny Health Network, Saint Vincent Hospital, Erie, PA.

Correspondence to: Dr. Dhimitri A. Nikolla, Department of Emergency Medicine, Allegheny Health Network, Saint Vincent Hospital, 232 West 25 th St., Erie, PA 16544; Email: dhimitri.nikolla@med.lecom.edu. 


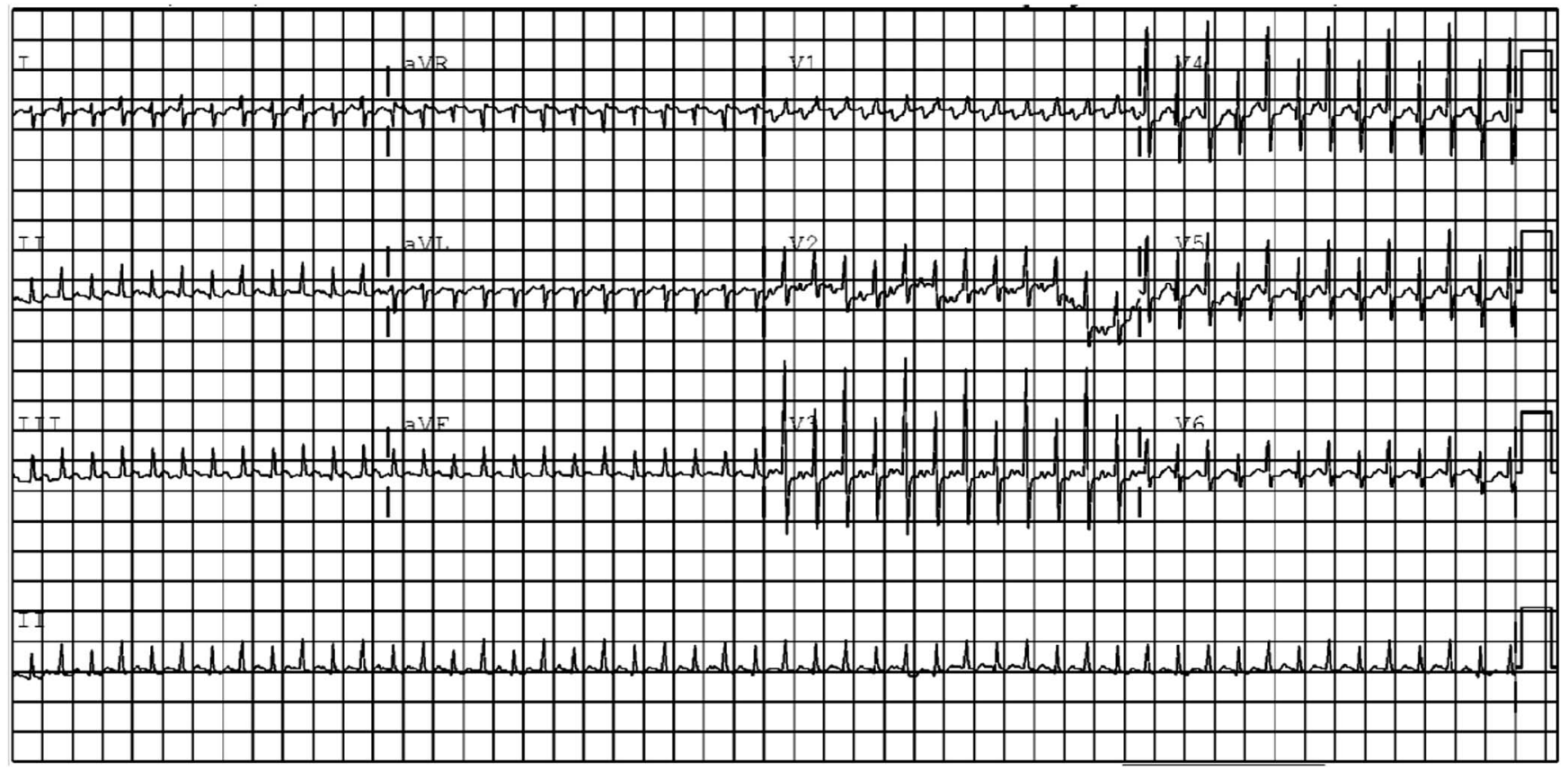

Figure 2. Patient's ECG at the rapid response.

D) Salicylate toxicity

E) Diabetic ketoacidosis

\section{ANSWER}

The correct answer is $C$ (paroxysmal SVT with acute congestive heart failure). Vagal maneuvers, including ice to the face and gently flipping him upside down were attempted without success. Because of the alternans, a limited bedside echocardiogram was performed showing no pericardial effusion or gross structural abnormalities. The patient was then given $0.7 \mathrm{mg}$ or roughly $0.1 \mathrm{mg} / \mathrm{kg}$ of adenosine, and the dysrhythmia converted to a normal sinus rhythm at 149 beats/minute without evidence of a delta wave or short PR interval for his age (normal: $82-141 \mathrm{msec}$ ) on a repeat ECG (Figure 3). ${ }^{1}$ No flutter waves or other ectopic beats were observed during the pause. The patient was transferred to the nearest pediatric hospital.

The patient was later diagnosed with SVT by his pediatric cardiologist and placed on propranolol prophylaxis. About 6 months later, he was seen again in the ED for tachycardia. His mother stated that she forgot to give him his propranolol the day prior and noticed that he appeared sleepy. When she checked his pulse, it was $>200$ beats/minute. She stated that she flipped him upside down, and the tachycardia resolved.
On examination at the repeat ED visit, he was afebrile with normal vital signs and no clinical signs of infection. His ECG (Figure 4) showed a normal sinus rhythm at 121 beats/minute without evidence of a delta wave or short PR interval for his age (normal: $86-151 \mathrm{msec}){ }^{1}$ In retrospect, the patient's initial dyspnea and "perihilar haziness" on chest radiograph (see Figure 1) at the first $\mathrm{ED}$ visit is likely more consistent with acute congestive heart failure rather than pneumonia, because of his lack of fever on presentation and knowledge of this second visit for recurrent SVT without signs of infection.

SVT is defined as a sustained, narrow complex tachycardia involving conduction through the atrial tissue or the atrioventricular node, otherwise originating above the atrioventricular junction., ${ }^{2,3}$ SVT occurs in as many as 1 in every 250 to 500 children but can easily be missed in infants who present with vague symptoms and when the dysrhythmia has temporarily subsided. ${ }^{2,4}$

Infants with SVT and resultant acute congestive heart failure can often have initial signs, symptoms, and findings suggestive of other pathology such as pneumonia, as in this case. Whereas older children may be able to relay symptoms of presyncope, syncope, palpitations, or chest discomfort, an infant cannot relay these specific symptoms concerning a dysrhythmia. Therefore, the diagnosis of paroxysmal SVT is difficult 


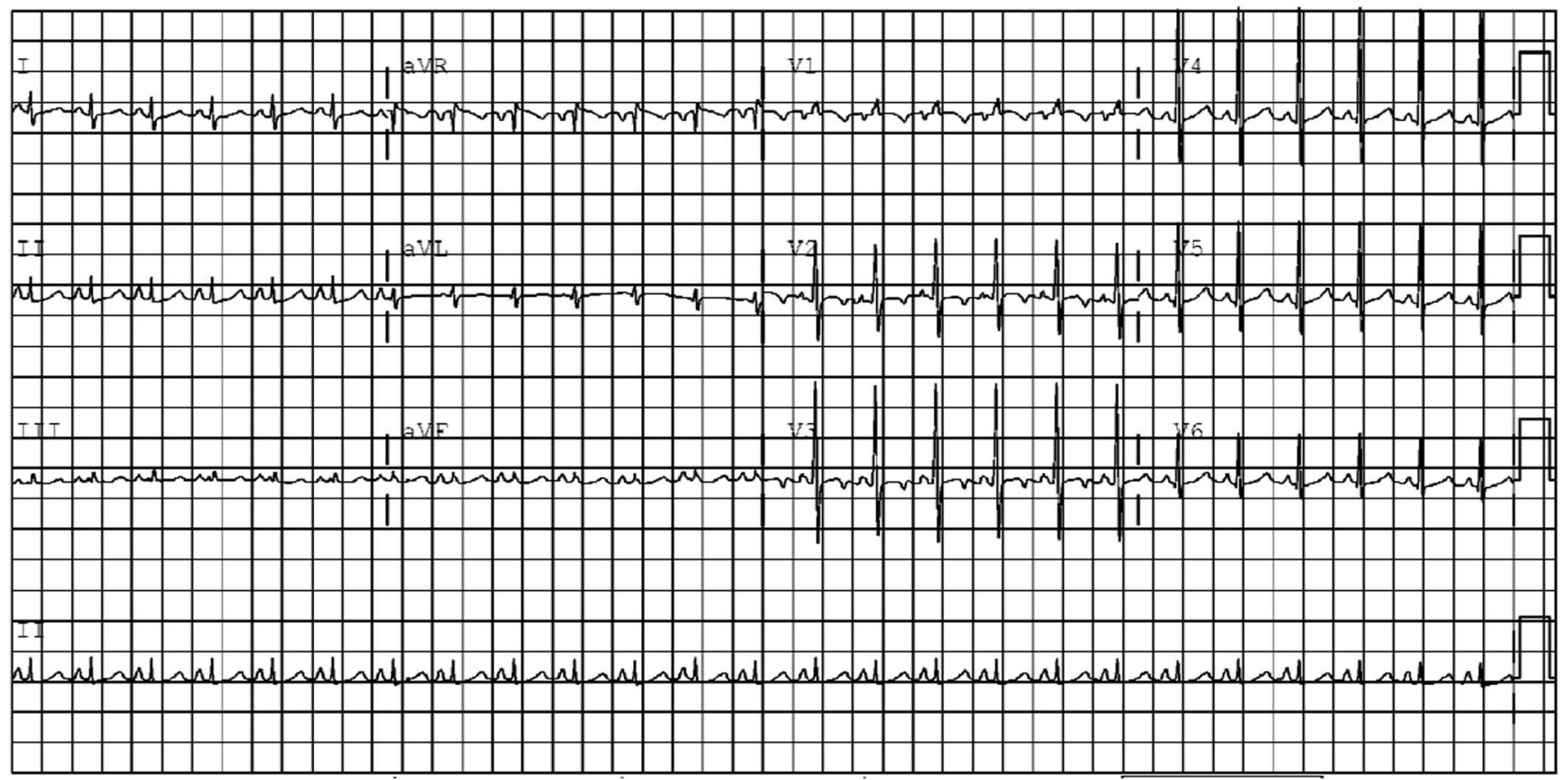

Figure 3. Patient's ECG after chemical cardioversion.

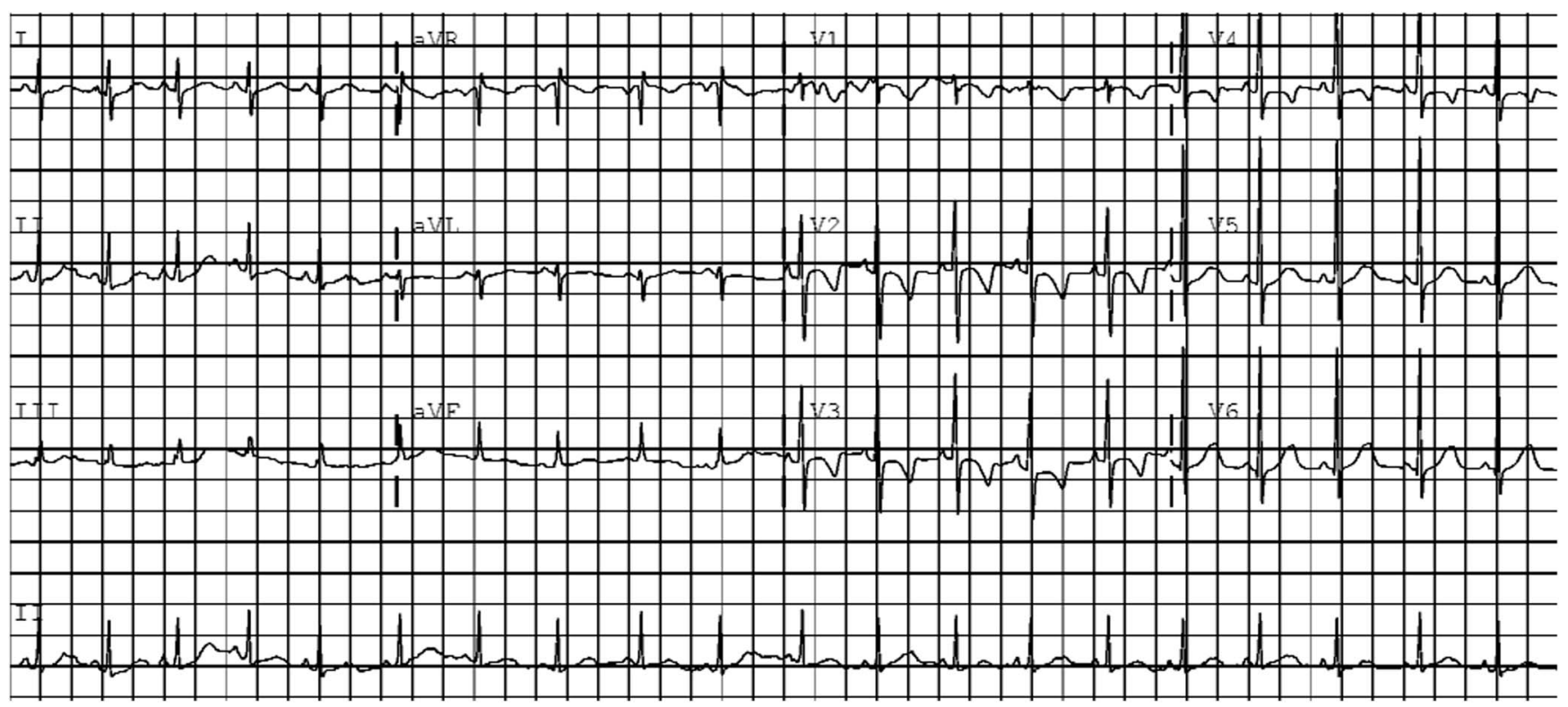

Figure 4. Patient's ECG at his repeat ED visit.

to make in infants, especially if the dysrhythmia has temporarily subsided. Symptoms of rapid breathing and poor feeding, described by the mother of the patient, can easily lead the clinician down an alternative diagnostic pathway away from SVT. ${ }^{3}$ Although the patient's hepatomegaly was a critical indication of his acute congestive heart failure secondary to $\mathrm{SVT}^{5}{ }^{5}$ it was not present on abdominal examination in the ED. It is also likely that the administration of an intravenous fluid bolus and several hours of maintenance fluids contributed to the hepatomegaly, making it more prominent later at the rapid response.

Laboratory and imaging studies can also be misleading. The systemic stress caused by SVT can create a 


\begin{tabular}{|c|c|}
\hline $\begin{array}{l}\text { Adenosine } \\
\text { responsive } \\
4,6-10\end{array}$ & SVT subtypes \\
\hline Yes & Orthodromic AVRT (e.g., WPW), AVNRT \\
\hline No & Sinus tachycardia, atrial tachycardia, atrial flutter \\
\hline Likely & $\begin{array}{l}\text { Orthodromic AVRT (e.g., PJRT), junctional } \\
\text { tachycardia }\end{array}$ \\
\hline \multicolumn{2}{|c|}{$\begin{array}{l}\text { AVRT = atrioventricular reentry tachycardia; AVNRT }=\text { atrioventricular node } \\
\text { reentry tachycardia; PJRT = permanent junctional reciprocating tachycardia; } \\
\text { SVT = supraventricular tachycardia; WPW = Wolff-Parkinson-White syndrome. }\end{array}$} \\
\hline
\end{tabular}

leukocytosis leading to a false positive indication of infection. Also, with SVT at rates greater than 250 beats/ minutes, the dysrhythmia can lead to severe congestive heart failure, ${ }^{4}$ producing vascular congestion on the chest $\mathrm{X}$-ray, which can be mistaken for a pneumonia. Therefore, it is critical for the emergency provider to consider paroxysmal SVT and other cardiac pathology in infants with pulmonary signs and symptoms.

Similarly, specific subtypes of SVT can be difficult to elucidate during the acute dysrhythmia. Our initial interpretation of the rapid response ECG was a 1:1 atrial flutter because of the $\mathrm{P}$ waves seen in V2-3 and the fast, constant rate of roughly 300 beats/minute (see Figure 2). However, atrial flutter should not have converted with adenosine, making other subtypes of SVT more likely (Table 1). ${ }^{4,6}$

This ambiguity in the rhythm is created by several factors. First, infants with SVT often have faster HRs than older children and adults. Rates can reach 220 to 320 beats/minute, making conditions, such as atrioventricular node reentry tachycardia (AVNRT), more difficult to distinguish from a 1:1 atrial flutter based off of the rate alone. ${ }^{2,4}$ Also, with elevated rates, it can be challenging to differentiate between anterograde and retrograde $\mathrm{P}$ waves, which help delineate the subtypes of SVT. Recording a rhythm strip immediately after vagal maneuvers or the administration of adenosine to look at P-wave location and morphology can help elucidate the diagnosis of specific SVT subtypes. ${ }^{4}$

Although adenosine is the most widely used abortive therapy for infantile SVT, vagal maneuvers, including carotid massage, facial cooling, ice water immersion, direct eyeball pressure, and the Valsalva maneuver for older children, are considered first-line if the infant is hemodynamically stable. ${ }^{3,11-13}$ If vagal maneuvers fail, adenosine is considered second-line, but it is contraindicated for irregular or polymorphic wide complex tachycardias because of the risk of conversion to ventricular fibrillation. ${ }^{11,13,14}$ Last, if the infant is hemodynamically unstable, electrical cardioversion is recommended. ${ }^{4,13}$

Paroxysmal SVT can be difficult to diagnose in infants, especially when the dysrhythmia has temporarily subsided. Vague symptoms and misleading laboratory and imaging findings can easily deceive providers. In addition, subtypes of SVT can be difficult to differentiate from one another in the acute setting; therefore, a systematic approach using vagal maneuvers and adenosine, if necessary, with a continuous rhythm strip, is essential to obtain the correct diagnosis.

Acknowledgments: Both authors have made substantial contributions to the concept and design of the manuscript, have partaken in the drafting and revising of the manuscript, and have approved the final version.

Competing interests: None declared.

\section{REFERENCES}

1. Rijnbeek PR, Witsenburg M, Schrama E, et al. New normal limits for the paediatric electrocardiogram. Eur Heart 7 2001;22(8):702-11.

2. Salerno JC, Seslar SP. Supraventricular tachycardia. Arch Pediatr Adolesc Med 2009;163(3):268-74.

3. Ashok TP, Sharma S, Jain M. Paroxysmal supraventricular tachycardia in the rural setting - case reports and review. Oman Med 7 2008;23(2):104-7.

4. Kantoch MJ. Supraventricular tachycardia in children. Indian 7 Pediatr 2005;72(7):609-19.

5. Macicek SM, Macias CG, Jefferies JL, et al. Acute heart failure syndromes in the pediatric emergency department. Pediatrics 2009;124(5):e898-904.

6. Marx JA, Hockberger RS, Walls RM, et al. (eds.) Rosen's emergency medicine: concepts and clinical practice. Philadelphia, PA: Mosby/Elsevier; 2010: 1048-55.

7. Glatter KA, Cheng J, Dorostkar P, et al. Electrophysiologic effects of adenosine in patients with supraventricular tachycardia. Circulation 1999;99:1034-40.

8. Belhassen B, Glick A, Laniado S. Comparative clinical and electrophysiologic effects of adenosine triphosphate and verapamil on paroxysmal reciprocating junctional tachycardia. Circulation 1988;77:795-805.

9. Till J, Shinebourne EA, Rigby ML, et al. Efficacy and safety of adenosine in the treatment of supraventricular tachycardia in infants and children. Br Heart 7 1989;62:204-11.

10. Bae EJ, Noh CI, Choi JY, et al. Late occurrence of adenosinesensitive focal junctional tachycardia in complex congenital heart disease. 7 Interv Card Electrophysiol 2005;12(2):115-22.

11. Chu PY, Hill KD, Clark RH, et al. Treatment of supraventricular tachycardia in infants: analysis of a large multicenter database. Early Hum Dev 2015;91(6):345-50. 
12. Wen ZC, Chen SA, Tai CT, et al. Electrophysiological mechanisms and determinants of vagal maneuvers for termination of paroxysmal supraventricular tachycardia. Circulation 1998;98(24):2716-23.

13. de Caen AR, Berg MD, Chameides L, et al. Part 12: Pediatric Advanced Life Support: 2015 American Heart Association guidelines update for cardiopulmonary resuscitation and emergency cardiovascular care. Circulation 2015;132(18 Suppl 2):S526-42.

14. Link MS, Berkow LC, Kudenchuk PJ, et al. Part 7: Adult Advanced Cardiovascular Life Support: 2015 American Heart Association guidelines update for cardiopulmonary resuscitation and emergency cardiovascular care. Circulation 2015;132(18 Suppl 2):S444-64. 